\title{
Direct and indirect therapeutic effect of traditional Chinese medicine as an add-on for non-proliferative diabetic retinopathy: a systematic review and meta-analysis
}

Xuedong An ${ }^{1,2+} \oplus$, De Jin ${ }^{1,2+}$, LiYun Duan ${ }^{1,2}$, Shenghui Zhao ${ }^{1,3}$, Rongrong Zhou ${ }^{1,2}$, Fengmei Lian ${ }^{\text {* }}$ and Xiaolin Tong ${ }^{1 *}$

\begin{abstract}
Background: Diabetic retinopathy (DR) is the leading cause of blindness in many countries. The current treatment for non-proliferative DR (NPDR) using Western medicine (WM) alone is insufficient. At present, the combination of NPDR treatment with traditional Chinese medicine (TCM) and WM is universally applied. We aimed to evaluate the effectiveness and safety of TCM as an add-on for NPDR using a systematic review and meta-analysis.

Method: Data from randomized controlled trials (RCTs) of TCM for NPDR treatment along with WM before July 6 , 2019, were collected from the China National Knowledge Infrastructure, Wanfang Database, China Biomedical Database, Pubmed, Embase, and Cochrane Library. Relevant data were extracted by two reviewers. I statistics was adopted to appraise heterogeneity. If $P^{2}<50 \%$ the fixed-effects model was employed, otherwise a random-effect model was employed. (PROSPERO: CRD42019134947)

Result: Eighteen RCTs (1522 patients) were included based on the inclusion and exclusion criteria. The results showed that compared with WM alone, TCM (including Compound Xueshuantong Capsule, Qiming Granule, and others) combined with WM for NPDR could improve the overall efficacy $[n=1686, R R 1.24(1.18,1.30), P<0.00001$, $\left.P^{2}=0 \%\right]$, and reduce the influence of risk factors related to NPDR, such as glycated hemoglobin level $[n=360, M D$ $-0.85(-1.28,-0.41), P=0.0001, P=72 \%]$, triglyceride $(P<0.00001)$, and total cholesterol $(P=0.0008)$. Moreover, no serious adverse events were reported.
\end{abstract}

Conclusion: Compared with WM alone, TCM + WM could significantly improve NPDR and also reduce the correlation levels of risk factors, such as hyperglycemia, dyslipidemia. However, the small sample included in the study might lead to a publication bias, and therefore, our results should be treated with caution.

Keywords: Traditional Chinese medicine, Additional drugs, Non-proliferative diabetic retinopathy, Meta-analysis, Direct treatment, Indirect treatment

*Correspondence: Ifm565@sohu.com; tongxiaolin@vip.163.com ${ }^{\dagger}$ Xuedong An and De Jin contributed equally and are co-first authors 1 Department of Endocrinology, Guang'anmen Hospital, China Academy of Chinese Medical Sciences, Beijing 100053, China

Full list of author information is available at the end of the article

\section{Background}

According to the International Diabetes Federation, the number of patients with diabetes mellitus (DM) worldwide has reached 415 million, and by 2040, the total number of patients will exceed 600 million. In China, the prevalence rate of DM has increased from $0.67 \%$ in 1980 to $10.4 \%$ in 2013 [1], and complications related to

(c) The Author(s) 2020. This article is licensed under a Creative Commons Attribution 4.0 International License, which permits use, sharing, adaptation, distribution and reproduction in any medium or format, as long as you give appropriate credit to the original author(s) and the source, provide a link to the Creative Commons licence, and indicate if changes were made. The images or other third party material in this article are included in the article's Creative Commons licence, unless indicated otherwise in a credit line to the material. If material is not included in the article's Creative Commons licence and your intended use is not permitted by statutory regulation or exceeds the permitted use, you will need to obtain permission directly from the copyright holder. To view a copy of this licence, visit http://creativeco mmons.org/licenses/by/4.0/. The Creative Commons Public Domain Dedication waiver (http://creativecommons.org/publicdomain/ zero/1.0/) applies to the data made available in this article, unless otherwise stated in a credit line to the data. 
DM will lead to greater economic and social burden in the future. Complications of DM include macrovascular complications (i.e. cardiovascular disease, stroke), microvascular complications (i.e. diabetic nephropathy, diabetic retinopathy (DR), and diabetic peripheral neuropathy). Among them, DR is a continuous process of microcirculation and lesion development. According to the American Academy of Ophthalmology Clinical Guidelines in 2006, DR is mainly divided into non-obvious DR, non-proliferative DR (NPDR), and proliferative DR (PDR), and is often accompanied by diabetic macular edema (DME). The quality of life, psychology, and social behavior are impaired in patients with PDR, incurring increased medical expenses [2]. Vision loss can also occur in the late stage of DME or PDR, with DR being one of the major causes of blindness in many countries [3].

There are many factors involved in the pathogenesis of DR: disease course, family inheritance, hyperglycemia, hyperlipemia, or hypertension $[4,5]$. For the treatment of DR, the most important factor is lowering of blood sugar levels. Studies have shown that when glycosylated hemoglobin (HbAlc) is reduced by $10 \%$ from baseline (such as $10 \%$ to $9 \%$ ), the progression of DR is reduced by 43\% [6]. As demonstrated by the United Kingdom Prospective Diabetes Study, patients with tightly controlled blood pressure have a significant protective effect on DR progression [7]. Hyperlipidemia is associated with an increased risk of DR in Chinese patients with T2DM, suggesting that control of blood lipids may reduce the risk of DR [8]. In the non-proliferative phase, the main treatments are oral medications, including calcium dobesilate (CD), intestinal kininogenase, and large doses of compound danshen dripping pills, while in the proliferative phase, laser surgery, and anti-vascular endothelial growth factor (VEGF) are needed. However, clinical research shows that current treatment, such as oral WM, still have certain drawbacks, are not suitable for all patients, and the effects are not significant. Laser surgery is a destructive treatment that only prevents the occurrence of blindness but does not improve the vision and fundus lesions in general, despite a recent trial that showed improvement of vision in some patients [9]. Even after VEGF injections, a relatively high proportion of patients (46\%) may still require local or grid laser treatment [10].

Traditional Chinese medicine (TCM) has been used for prevention and treatment of chronic diseases for nearly 2000 years and has an indelible contribution. Significant progress has been made in the treatment of DM and its complications. Many studies have shown that Jiangtang Tiaozhi Fang can effectively reduce the levels of blood sugar and lipids [11]. Further, Compound Danshen Dripping Pills are used to treat NPDR [12]. Nowadays, the combination of TCM and WM is more common in clinical practice, which is also applied to NPDR. Randomized clinical trials (RCTs) have shown that this combination is feasible and has good curative effects [12]. However, there is currently no systematic review to prove its safety and effectiveness, and there is still a lack of high-level evidence. Therefore, we systematically evaluated the efficacy and safety of TCM as an additional drug (add-on) for the treatment of NPDR, in order to provide high-level, referenceable evidence for the selection of clinical drugs.

\section{Methods}

This study was conducted and reported in accordance with the Preferred Reporting Project (PRISMA) guidelines for systematic reviews and meta-analysis [13]. The PROSPERO registration number is CRD42019134947.

\section{Search strategy and data organization}

The Chinese Knowledge Network, Wanfang Database, China Biomedical Database, Pubmed, Embase, and Cochrane Library were searched for RCTs of TCM for the treatment of NPDR in combination with WM before July 6, 2019.

The search used a combined text and $\mathrm{MeSH}$ heading search strategy, and the search terms included "early or non-proliferative phase" and "diabetic retinopathy" and "randomized controlled trial or randomized".

Search Strategy: (((((Non proliferative[Title/Abstract]) OR Non-proliferative [Title/ Abstract]) OR early[Title/ Abstract $]))$ AND (((("Diabetic Retinopathy"[Mesh]) OR Diabetic Retinopathy[Title/Abstract]) OR Diabetic Retinopathies[Title/Abstract]) OR Retinopathies, Diabetic[Title/Abstract]) OR Retinopathy, Diabetic[Title/Abstract]))) AND (randomized controlled trial[Publication Type] OR randomized[Title/Abstract] OR placebo[Title/Abstract]).

The titles and abstracts included in this work were screened by Xuedong An and Fengmei Lian, respectively. Differences were resolved through discussion.

\section{Inclusion criteria}

Studies were included if they met the following $\mathrm{PICO}(\mathrm{S})$ (participants, intervention, comparators, outcomes (study designs)) criteria:

1. Participants: The participants had NPDR; no gender and race restrictions.

2. Intervention: The TCM+WM group was treated with TCM on the basis of WM.

3. Comparator: The WM group was treated with WM.

4. Outcome: Direct outcomes included overall efficacy, visual acuity, and retinal fundus examination. Indirect outcomes included fasting blood glucose, 2-h 
postprandial blood glucose, glycosylated hemoglobin, triglyceride, total cholesterol, high-density lipoprotein, and low-density lipoprotein levels. The safety outcome was adverse events.

5. Study design: The study type was a randomized controlled trial (blinded or non-blinded).

Clinical studies were independently evaluated by two investigators (Xuedong An and Fengmei Lian) for methods (e.g., correct randomization), interventions, patient selection, efficacy and safety outcomes, to ensure that the studies were eligible for inclusion in our study.

\section{Exclusion criteria}

Studies were excluded for: duplicate publication, only abstract or lack of data available, and inability to obtain full-text articles or to extract data for research.

\section{Data extraction}

Data, including basic information such as gender, age, duration of disease, basic treatment, major outcome indicators, medication, intervention time, case shedding, and adverse events were collected by Xuedong An and Fengmei Lian.

\section{Assessing the risk of bias and the quality of evidence}

The RCTs included in this review were assessed as low, high, or unclear risk of bias using the Cochrane Bias Risk Tool (CRBT), which included random sequence generation, allocation concealment, blinding, incomplete data, selective reporting, and other biases. Xuedong An and Fengmei Lian independently applied the CRBT to assess the risk of bias in each study. Controversial opinions were resolved through discussion.

\section{Statistical analysis of data}

All results were analyzed using RevMan 5.2 software provided by the Cochrane Collaboration [14]. The aggregated continuous variable results were analyzed by the mean difference (MD) and 95\% confidence interval (CI); the results were summarized and analyzed by relative risk (RR) and $95 \% \mathrm{CI}$, while $\mathrm{I}^{2}$ statistics were used to assess heterogeneity. If $I^{2} \leq 50 \%$, the fixed effect model was used, otherwise the random effect model was employed. In addition, if the primary outcome data were missing or the trial was incomplete, the corresponding author was contacted. We also used the funnel plot to assess potential publication bias according to the Cochrane Handbook [15].

\section{Results}

Basic research and quality evaluation

In the literature search, 2938 potentially related articles were found (PubMed: 621, Embase: 436, Cochrane: 1275, China Knowledge Network: 355, Wanfang Database: 143, Chinese Medical Database: 108) (Fig. 1).

Finally, 18 studies met the inclusion criteria for this review [16-33], including 1522 patients (763 in the $\mathrm{TCM}+\mathrm{WM}$ group and 759 in the WM group). Commonly used WM are CD and Yinxingdamo Injection, and commonly used TCM include Qiming Granule, and Compound Xueshuantong Capsule (Table 1). A total of 16 studies reported total efficacy $[16-25,27$, 29-33], seven reported vision [17, 19, 20, 23, 26, 29, 31], four, fundus efficacy [17, 26, 28, 29], five, fasting blood glucose (FBG) $[17,26,28,29,33]$, three reported 2 h-blood glucose (2hPG) [26, 29, 33], five, HbAlc [17, $26,28,29,33]$, four, triglycerides (TG) [17, 26, 28, 29], five, total cholesterol (TC) [17, 26, 28, 29, 31], three, high density lipoprotein (HDL) $[17,28,31]$, and five, low-density lipoprotein (LDL) [17, 26, 28, 29, 31]. Randomization was mentioned in all studies, but only seven studies showed how to generate random distribution sequences [16, 18, 19, 22, 23, 30,33]. None of the studies presented information related to allocation hiding and blinding methods (Figs. 2, 3).

\section{Main outcomes \\ Overall efficacy}

The overall efficacy in all studies showed homogeneity $\left(I^{2}=0 \%\right)$. Statistical data were obtained by using a fixed effect model. The results showed that the overall efficacy of TCM (including Compound Xueshuantong Capsule, Qiming Granule, and others) + WM in the treatment of NPDR was significantly better than that of WM alone $[\mathrm{n}=1686, \mathrm{RR} 1.24(1.18,1.30), P<0.00001$, $\left.I^{2}=0 \%\right]$ (Fig. 4).

\section{Vision}

There was no difference in the vision level between the $\mathrm{TCM}+\mathrm{WM}$ group and WM group before intervention $(P<0.27)$. The results of vision after intervention were heterogeneous $\left(I^{2}=95 \%\right)$. Data were analyzed by a random effect model. The results showed that compared with WM alone, TCM (including Qiming Granule and others) + WM treatment of NPDR significantly improved vision $[\mathrm{n}=640, \mathrm{MD} 0.16(0.06,0.27)$, $\left.P=0.003, I^{2}=95 \%\right]$ (Figs. 5, 6).

\section{Retinal fundus}

The results showed that the retinal fundus effect showed homogeneity $\left(I^{2}=0 \%\right)$. Statistical data were 


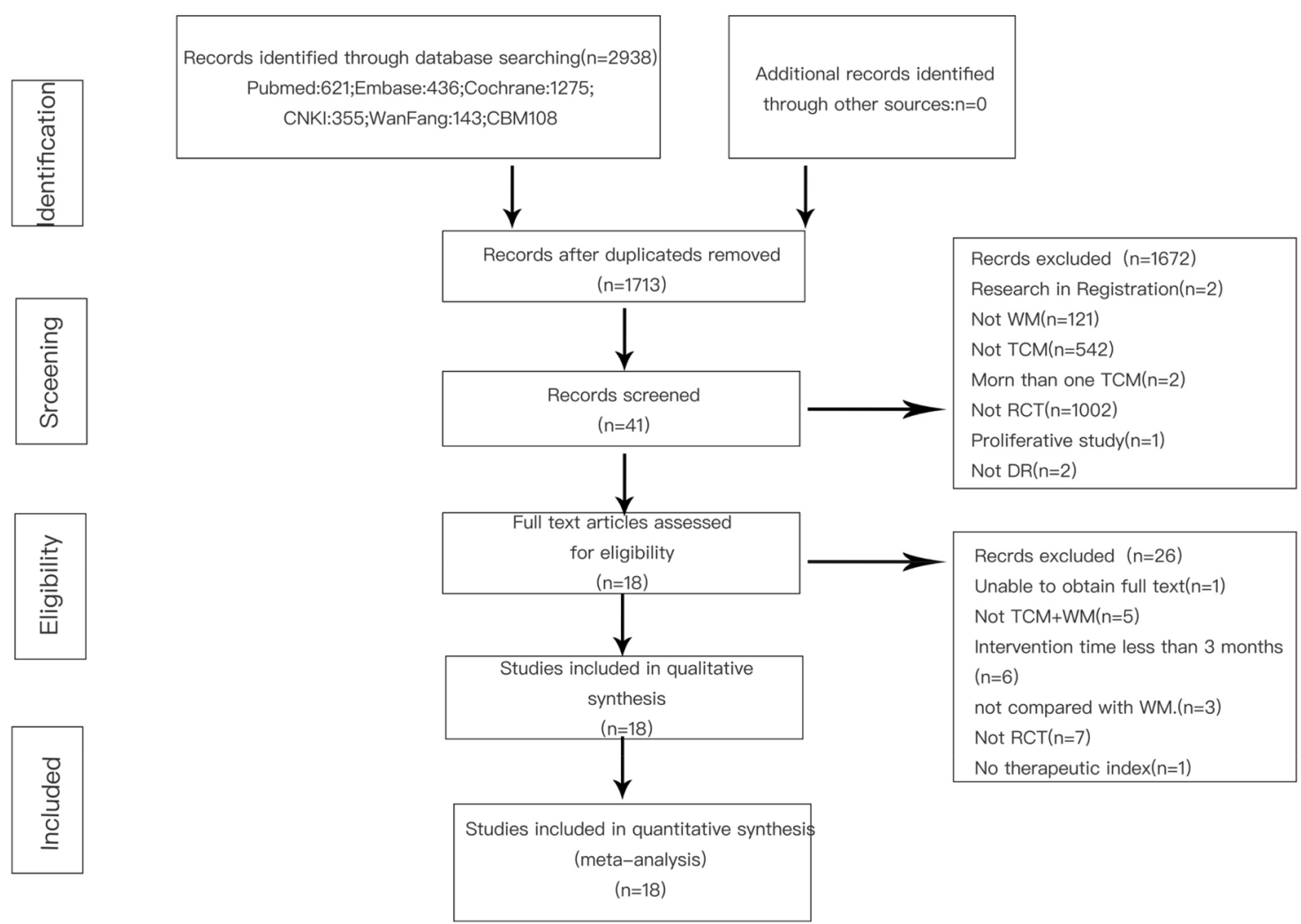

Fig. 1 The study screening process

obtained by using a fixed effect model. The results showed that compared with WM alone, TCM $+\mathrm{WM}$ in the treatment of NPDR fundus significantly improved $\left[\mathrm{n}=553\right.$, RR $\left.1.30(1.19,1.42), P<0.00001, I^{2}=0 \%\right]$ (Fig. 7).

\section{FBG}

There was no difference in the FBG level between the WM group and the TCM + WM group before intervention $(P=0.16)$. The results of FBG showed heterogeneity in the two groups after intervention $\left(I^{2}=67 \%\right)$. Statistical data were obtained by a random effect model. The results showed that compared with WM alone, TCM + WM could effectively reduce the FBG level in patients with NPDR $[\mathrm{n}=360, \mathrm{MD}-0.56(-0.91,-0.22), P=0.001$, $\left.I^{2}=67 \%\right]$ (Figs. 8, 9).

\section{2hPG}

There was no difference in the 2hPG level between the WM group and the TCM + WM group $(P=0.71)$. The results showed that the $2 \mathrm{hPG}$ level after intervention showed homogeneity $\left(I^{2}=0 \%\right)$. Statistical data were obtained by using a fixed effect model. The results showed that compared with WM alone, TCM+WM could effectively reduce the $2 \mathrm{hPG}$ level after intervention in patients with NPDR [n=194, MD $-1.12(-1.62$, $-0.61), P<0.0001, I^{2}=0 \%$ ] (Figs. 10, 11).

\section{HbAlc}

There was no difference in the HbAlc levels between the WM group and the TCM + WM group before intervention $(P=0.16)$. The results showed that the HbAlc level after intervention showed heterogeneity $\left(I^{2}=72 \%\right)$. Data were analyzed by a random effect model. The results showed that TCM $+\mathrm{WM}$ could effectively reduce the level of HbAlc compared with WM alone $[\mathrm{n}=360$, MD $-0.85(-1.28,-0.41), P=0.0001, I^{2}=72 \%$ ] (Figs. 12, 13).

TG

There was no difference in the TG level between the WM group and the TCM + WM group before intervention $(P=0.53)$. Studies showed that after intervention, the results of TG showed heterogeneity $\left(I^{2}=69 \%\right)$. A random effect model was used to analyze the data. The results showed that compared with WM alone, TCM + WM, but not Qiming Granule $(P=0.23)$, could effectively reduce 


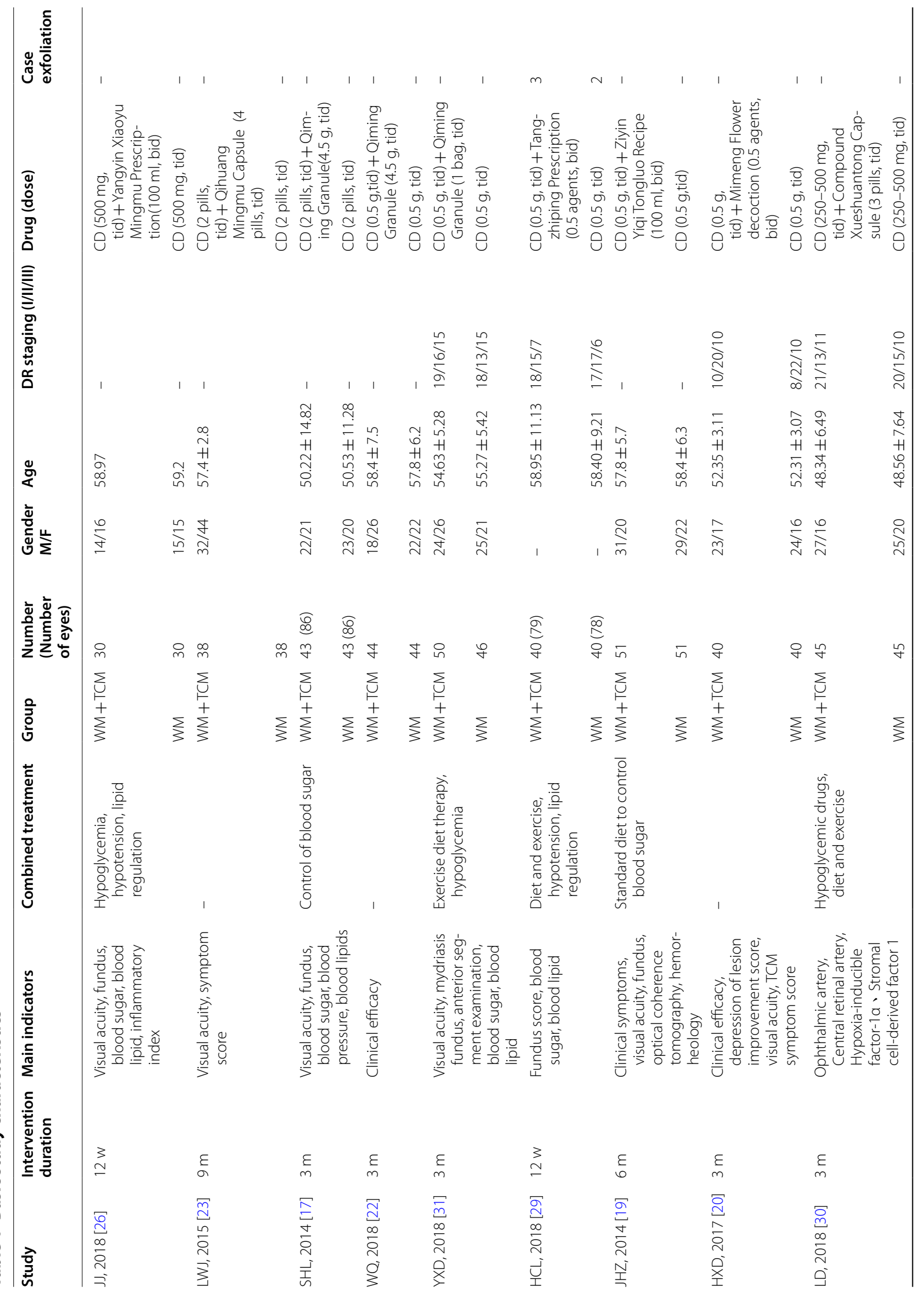




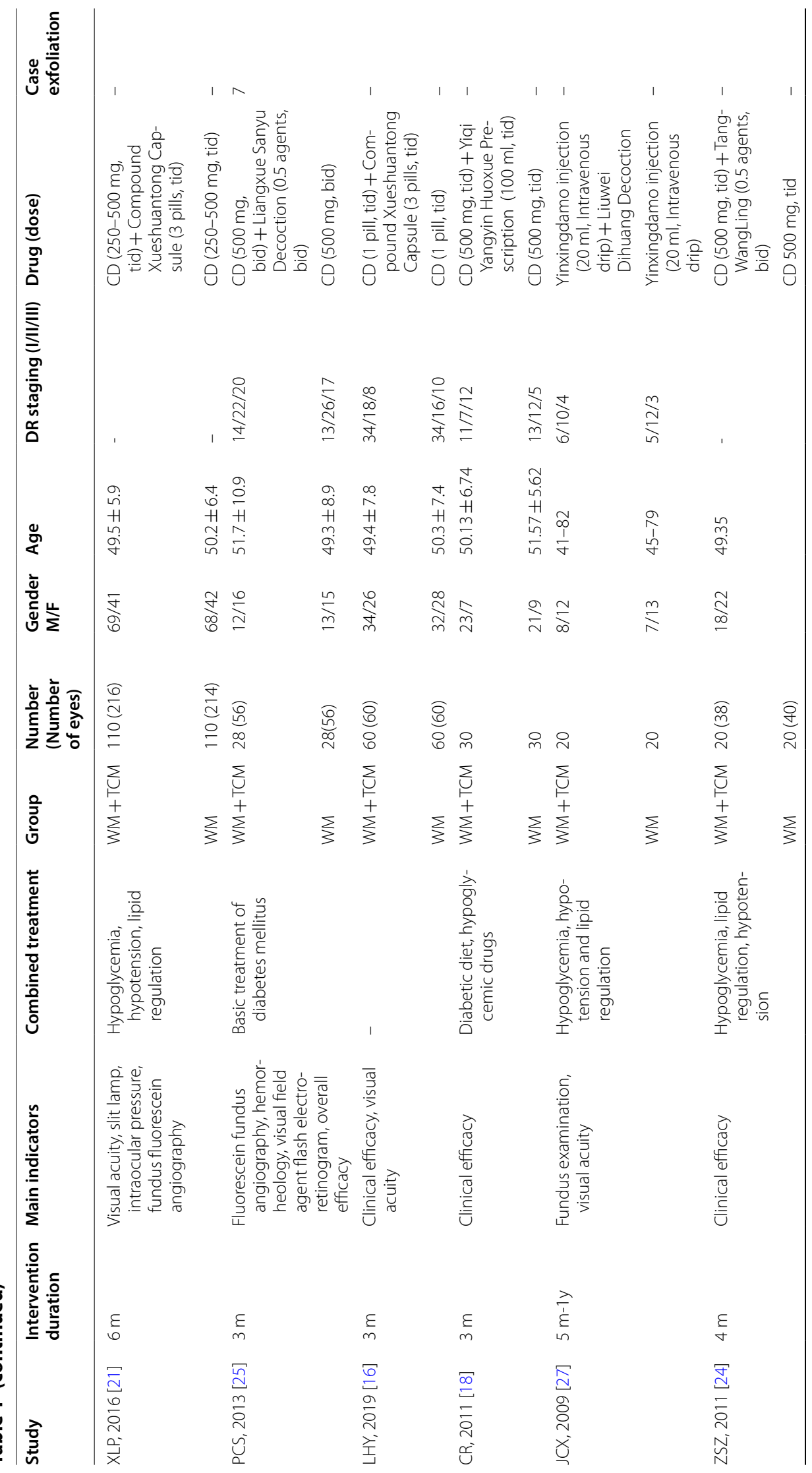




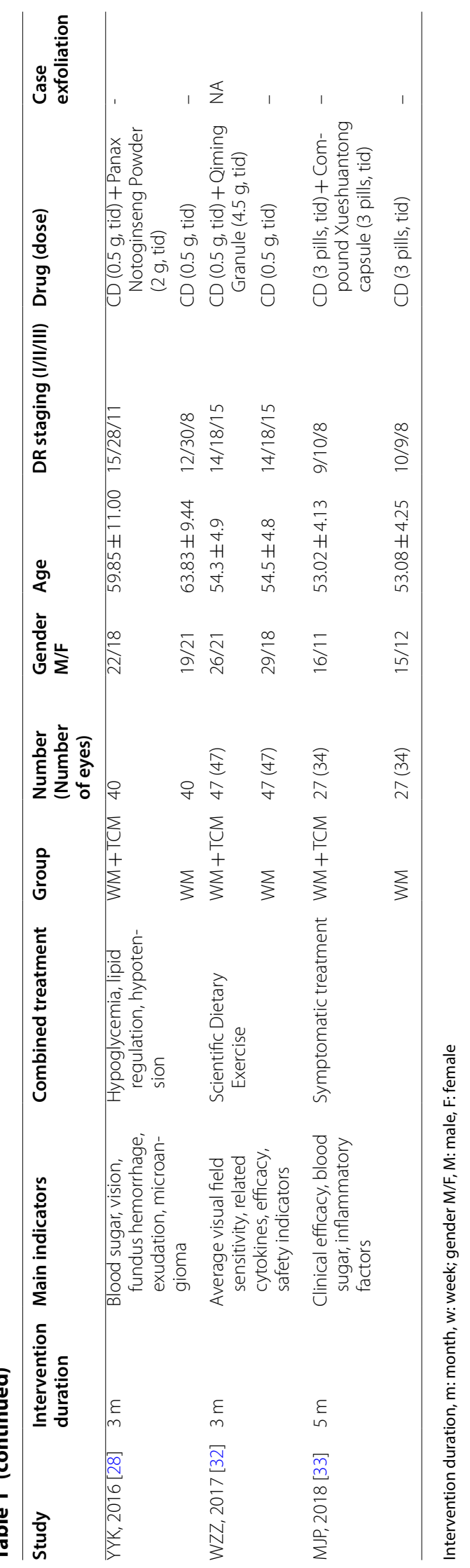




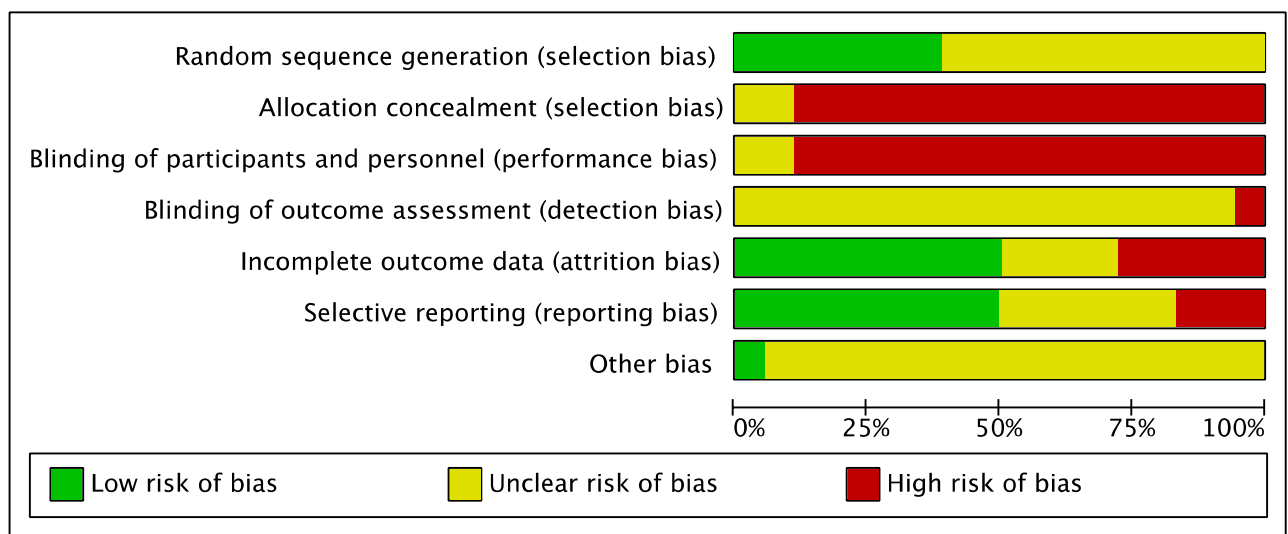

Fig. 2 Quality assessment of the included trials-Risk of bias graph

TG level in patients with NPDR $[\mathrm{n}=220, \mathrm{MD}-0.65$ $(-0.79,-0.51), P<0.00001, I^{2}=0 \%$ ] (Figs. 14, 15).

$T C$

There was no difference in the TC level between the WM group and the TCM $+\mathrm{WM}$ group before intervention $(P=0.10)$. All studies showed that TC after intervention showed heterogeneity $\left(I^{2}=91 \%\right)$. A random effect model was used to analyze the data. The results showed that TCM+WM could effectively reduce TC level in patients with NPDR compared with WM alone $[\mathrm{n}=220$, MD $\left.-0.66(-1.05,-0.27), P=0.0008, I^{2}=71 \%\right)$, but not Qiming Granule $(P=0.15)$ (Figs. 16, 17).

\section{$H D L$}

There was no difference in the HDL levels between the WM group and the TCM + WM group before intervention $(P=0.96)$. The results showed that after intervention, HDL showed heterogeneity $\left(I^{2}=99 \%\right)$. The data were analyzed by a random effect model. Figure 19 shows no difference in the HDL level between the WM group and the TCM + WM group after intervention $[\mathrm{n}=262$, MD $0.48(-0.46,1.41), P=0.32, I^{2}=99 \%$ ] (Figs. 18, 19).

\section{$L D L$}

There was no difference in the LDL levels between the WM group and the TCM + WM group before intervention $(P=0.32)$. The results showed that after intervention, LDL showed heterogeneity $\left(I^{2}=87 \%\right)$. Statistical data were obtained by a random effect model. The results showed that compared with WM alone, TCM + WM could effectively reduce LDL levels in patients with NPDR [n=402, MD $-0.44(-0.76,-0.11), P=0.009$, $\left.I^{2}=87 \%\right]$ (Figs. 20, 21).

\section{Adverse events}

Seven studies referred to adverse events $[17,20,21,26$, 31-33], with only one study reporting two cases of nausea and two cases of loss of appetite in the TCM + WM group, and two cases of stomach discomfort and three cases of loss of appetite in the WM group [20]. There was no difference between the two groups. No follow-up treatment for the adverse reactions was mentioned in any studies.

\section{Publication bias}

Funnel charts were used to investigate the publication bias. The funnel charts of the overall efficacy and fundus outcomes were basically symmetrical, indicating potential publication bias. Unpublished research may be considered a factor in publication bias (Figs. 22, 23).

\section{Discussion}

The Wisconsin Epidemiologic Study of Diabetic Retinopathy reported that approximately $75 \%$ of DM patients developed DR 10 years after diagnosis, while approximately two-thirds of patients with DR at baseline progressed to more severe DR stages, with $20 \%$ developing PDR or MDE [34]. With an increasing incidence of DM, the number of patients with DR is expected to increase from 126.6 million in 2010 to 191 million in 2030 . According to current estimates, the number of DR with visual threat is expected to increase from 37.3 to 56.3 million [35]. Moreover, the cost of DR is more than half that of non-DR. To sum up, DR has resulted in a tremendous social and economic burden.

At present, the most effective intervention for DR is early screening (i.e. using fundus photography, and fundus fluorescence angiography) and early diagnosis. Studies have shown that standardized, national DR screening 


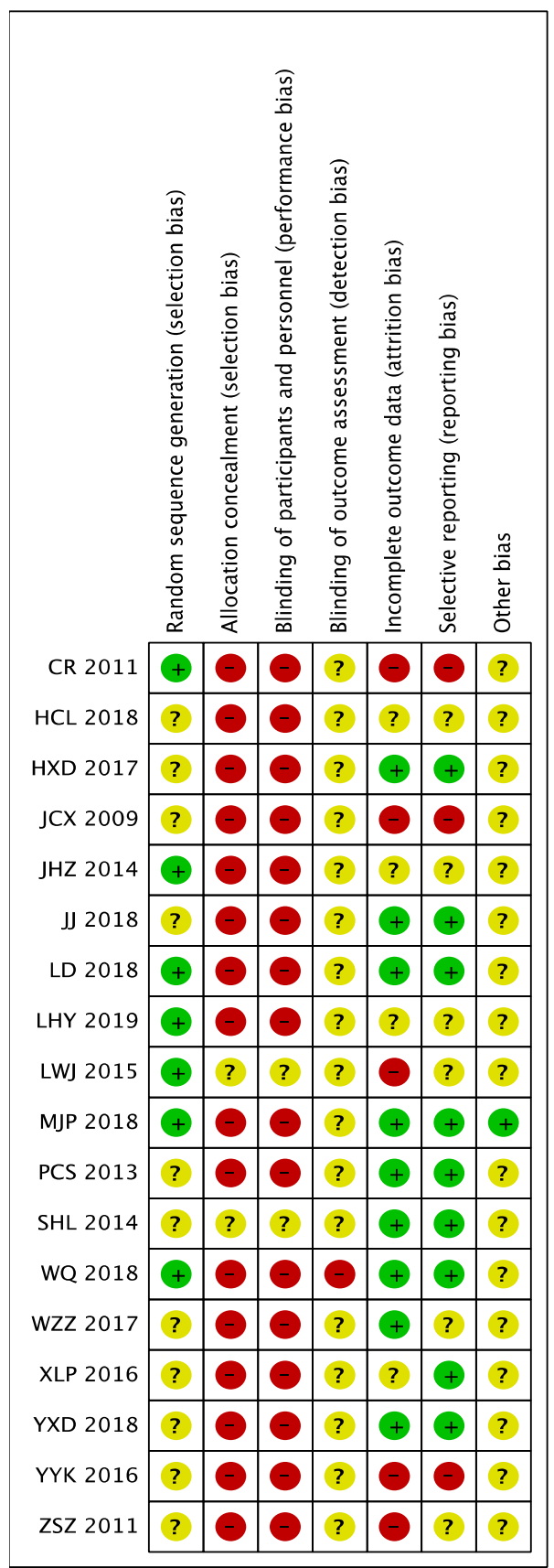

Fig. 3 Quality assessment of included trials-Risk of bias summary

can reduce the blindness rate in patients with DM up to $30-50 \%$ [36]. At the same time, the DM duration, hyperglycemia and hypertension are the most relevant risk factors for DR. Previous epidemiological and clinical studies have shown that NPDR can reduce the risk and progression of DR by controlling blood sugar and blood pressure levels [37]. Strict blood pressure control can reduce the risk of DR blindness by $47 \%$ [38]. However, the current understanding of DR risk factors is still insufficient because current risk factors are not applicable to all patients [39]. For example, HbA1c may account for only $10 \%$ of DR risk, blood pressure and serum TC may account for $<10 \%$ [40], and family inheritance for about 25-50\% [41]. In fact, studies have shown that DR does not occur in some patients with poor blood sugar and/ or blood pressure control [42], while other patients with properly controlled blood sugar levels may have severe DR [43], suggesting that other unknown risk factors also play an important role.

In the non-proliferative phase, oral $\mathrm{CD}$ and pancreatic kallikrein are commonly used. CD can improve retinal microneuropathy, retinal hemorrhage, exudates, and whole blood viscosity [44], by a mechanism related to the decrease of serum endothelin-1 and high-sensitivity C-reactive protein levels $[45,46]$.

For PDR, treatments include laser surgery, vitrectomy, tractive retinal detachment, and injection of antiangiogenic factors or application of steroid hormones with DME [39]. Retinal photocoagulation can effectively inhibit and treat retinal neovascularization and reduce the blindness rate by $50-60 \%$ [47]. Laser surgery is a destructive treatment, which can only block blindness, but cannot improve vision or fundus lesions of patients. Anti-VEGF injection can lead to intraocular inflammation, hemorrhage, elevated intraocular pressure, and loss of retinal ganglion cells. Corticosteroid hormones prevent vascular leakage by reducing VEGF secretion and release of inflammatory cytokines. However, the incidence of corticosteroid complications is high, most commonly an increase in the intraocular pressure and cataract formation [48]. Therefore, current treatment methods cannot solve this problem with DR treatment.

Because of its simplicity, convenience, cheapness, and testing, TCM has played an indelible role in disease prevention and treatment. In the actual clinical setting, its use in combination with WM can increase the efficacy, reduce adverse events, and even reduce the dosage of WM. For the treatment of DR, Qiming Granule is commonly used, which can relieve retinal hypoxia and ischemia by increasing the retinal blood flow and improving blood circulation [49], and also lower the HbAlc level [50]; Compound Xueshuantong Capsule can protect DR by regulating the Hippo pathway [51], and reducing the VEGF expression, aldose reductase activity, whole blood viscosity and plasma viscosity [52], and lowering blood sugar levels [53].

Based on the screening criteria, 18 RCT studies were included for quality evaluation. The results show that the overall quality of research is low. Compared with WM alone, statistical results showed that TCM + WM had significant effects on clinical efficacy, visual acuity, fundus 


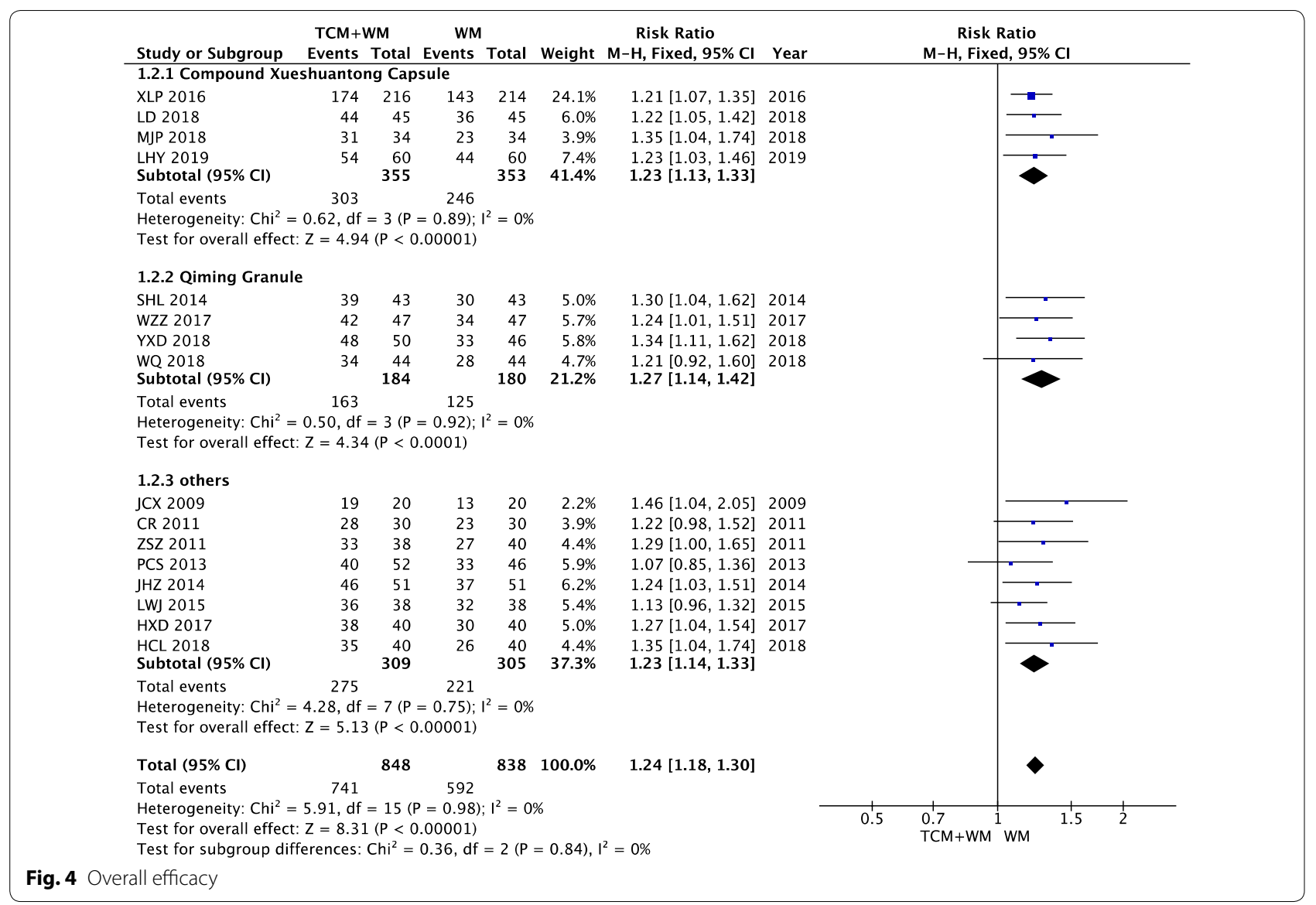

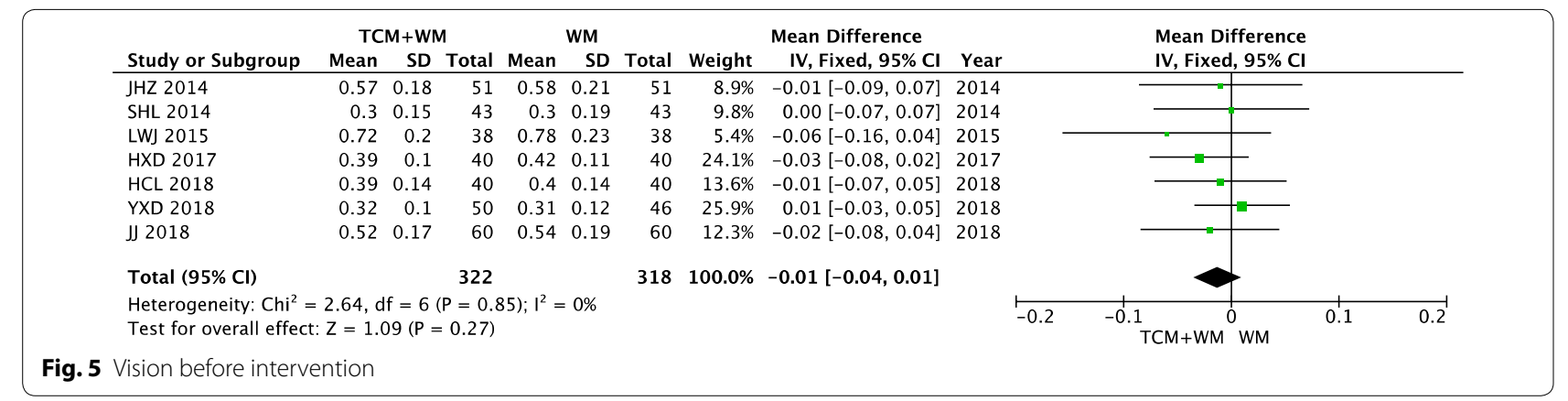

improvement, and related risk factors (i.e. blood sugar and blood lipid, but not blood pressure). Seven studies discussed the adverse events. Only one study indicated gastrointestinal discomfort, and there was no significant difference between the TCM + WM and the WM groups. No serious adverse events were reported, indicating that addition of TCM to WM for the treatment of NPDR is safe. At the same time, the results showed a great heterogeneity in the statistical analysis of visual acuity, FBG, 2hPG, HbAlC, TG, TC, HDL and LDL, probably due to factors such as fewer patients included in the study and incomplete unification of detection criteria.

Often, clinical efficacy is used to evaluate drug effects. The evaluation criteria for clinical efficacy include visual acuity, fluorescence angiography microangioma, fundus hemorrhage, exudation, edema and other symptoms. For patients with NPDR alone, clinical symptoms are mostly nor present, and they are mainly diagnosed through fundus photography, fluorescence angiography to reveal microangioma, hemorrhage spots, hard 


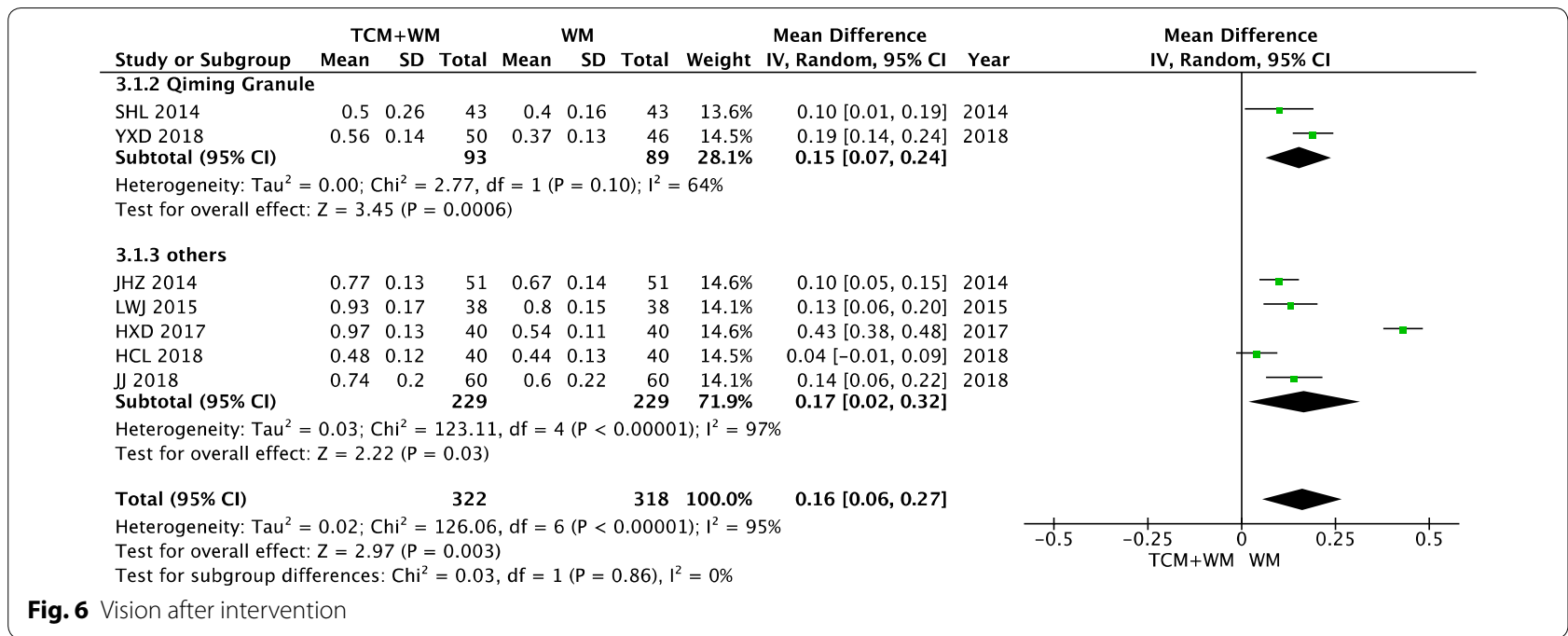

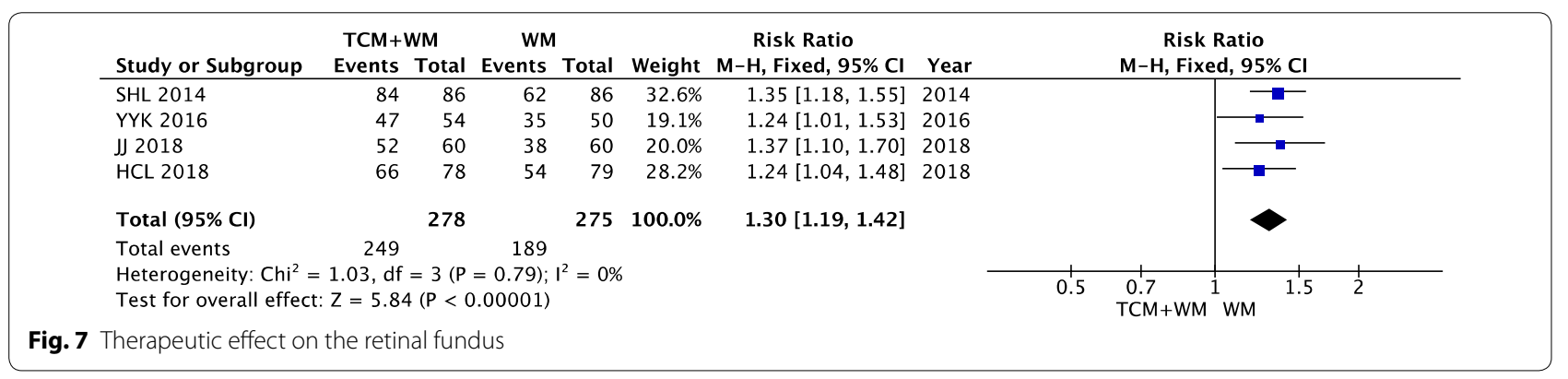

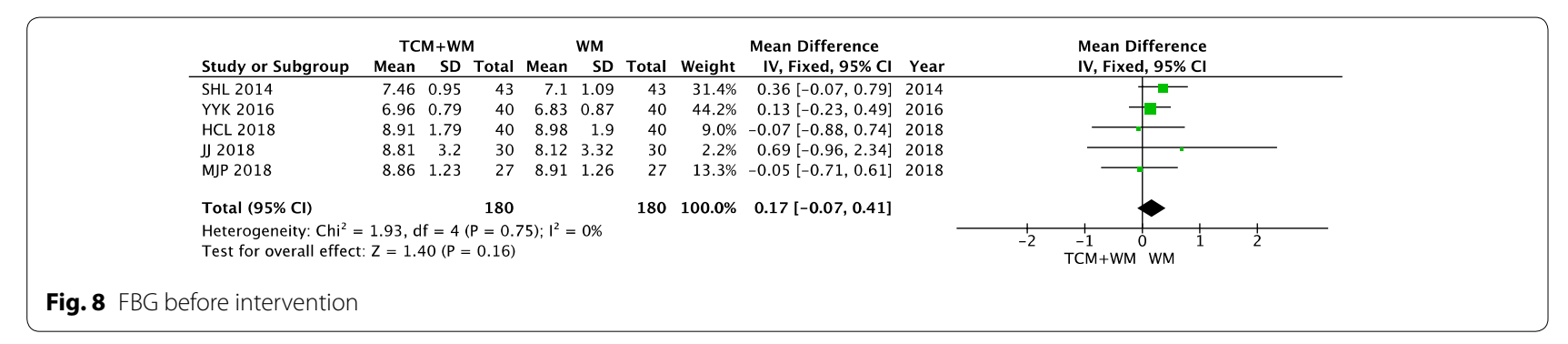

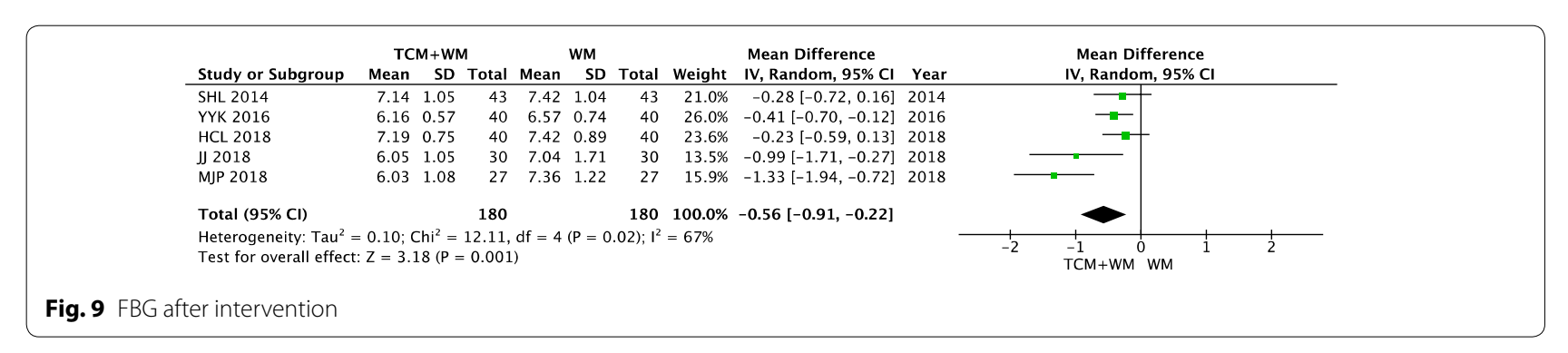




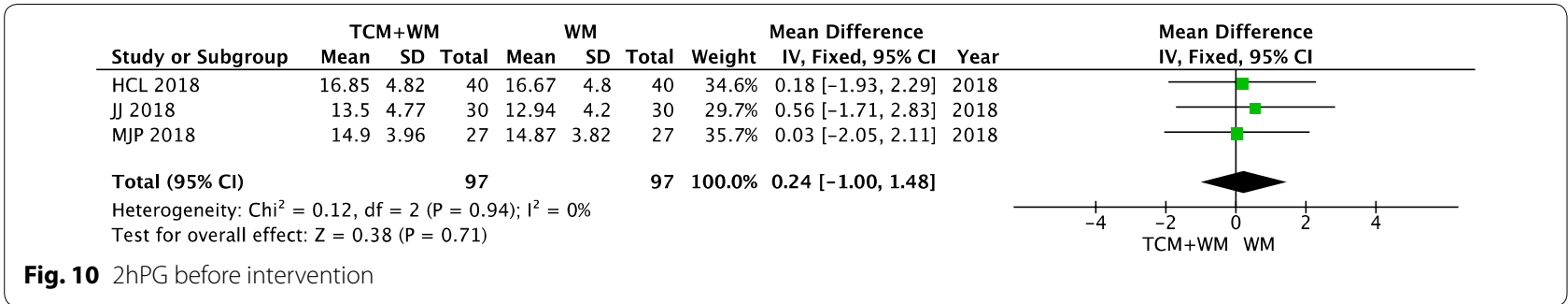

Fig. $102 \mathrm{hPG}$ before intervention

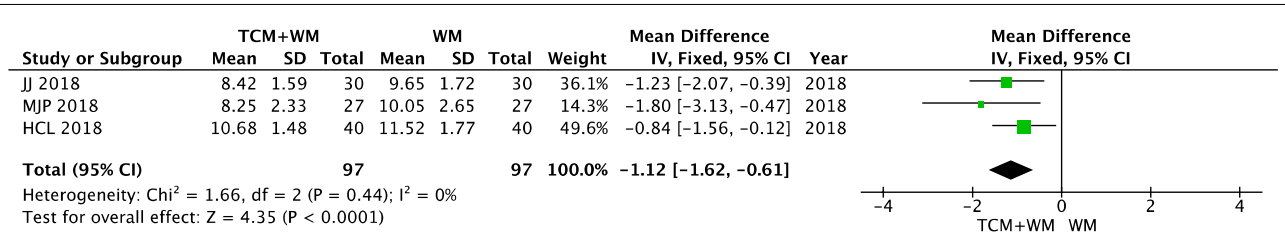

Fig. $112 \mathrm{hPG}$ after intervention

\begin{tabular}{|c|c|c|c|c|c|c|c|c|c|}
\hline \multirow[b]{2}{*}{ Study or Subgroup } & \multicolumn{3}{|c|}{$\mathrm{TCM}+\mathrm{WM}$} & \multicolumn{3}{|c|}{ WM } & \multicolumn{3}{|c|}{ Mean Difference } \\
\hline & Mean & SD & Total & Mean & SD & Total & Weight & IV, Random, $95 \% \mathrm{CI}$ & Year \\
\hline SHL 2014 & 6.39 & 1.08 & 43 & 7.45 & 1.82 & 43 & $22.7 \%$ & $-1.06[-1.69,-0.43]$ & 2014 \\
\hline YYK 2016 & 6.53 & 0.81 & 40 & 6.38 & 0.99 & 40 & $28.3 \%$ & $0.15[-0.25,0.55]$ & 2016 \\
\hline MJP 2018 & 9.82 & 2.21 & 27 & 9.87 & 2.16 & 27 & $12.7 \%$ & $-0.05[-1.22,1.12]$ & 2018 \\
\hline HCL 2018 & 9.03 & 1.67 & 40 & 8.94 & 1.68 & 40 & $20.4 \%$ & $0.09[-0.64,0.82]$ & 2018 \\
\hline 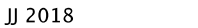 & 9.09 & 1.75 & 30 & 8.91 & 2.03 & 30 & $15.9 \%$ & $0.18[-0.78,1.14]$ & 2018 \\
\hline Total $(95 \% \mathrm{Cl})$ & & & 180 & & & 180 & $100.0 \%$ & $-0.16[-0.69,0.37]$ & \\
\hline
\end{tabular}

Fig. $12 \mathrm{HbAlc}$ before intervention

\begin{tabular}{|c|c|c|c|c|c|c|c|c|c|}
\hline \multirow[b]{2}{*}{ Study or Subgroup } & \multicolumn{3}{|c|}{$\mathrm{TCM}+\mathrm{WM}$} & \multicolumn{3}{|c|}{ WM } & \multicolumn{3}{|c|}{ Mean Difference } \\
\hline & Mean & SD & Total & Mean & SD & Total & Weight & IV, Random, $95 \% \mathrm{CI}$ & \\
\hline SHL 2014 & 6.09 & 1.04 & 43 & 7.5 & 1.03 & 43 & $23.2 \%$ & $-1.41[-1.85,-0.97]$ & \\
\hline YYK 2016 & 5.86 & 0.75 & 40 & 6.22 & 0.85 & 40 & $25.3 \%$ & $-0.36[-0.71,-0.01]$ & 20 \\
\hline HCL 2018 & 6.96 & 0.81 & 40 & 7.62 & 0.97 & 40 & $24.3 \%$ & $-0.66[-1.05,-0.27]$ & 20 \\
\hline J J 2018 & 7.37 & 1.18 & 30 & 8.25 & 1.73 & 30 & $16.0 \%$ & $-0.88[-1.63,-0.13]$ & \\
\hline MJP 2018 & 6.15 & 1.76 & 27 & 7.29 & 2.08 & 27 & $11.3 \%$ & $-1.14[-2.17,-0.11]$ & \\
\hline Total $(95 \% \mathrm{Cl})$ & & & 180 & & & 180 & $100.0 \%$ & $-0.85[-1.28,-0.41]$ & \\
\hline
\end{tabular}

Fig. $13 \mathrm{HbAlc}$ after intervention

\begin{tabular}{|c|c|c|c|c|c|c|c|c|c|c|c|c|}
\hline \multirow[b]{2}{*}{ Study or Subgroup } & \multicolumn{3}{|c|}{$\mathrm{TCM}+\mathrm{WM}$} & \multicolumn{3}{|c|}{ WM } & \multicolumn{3}{|c|}{ Mean Difference } & \multirow{2}{*}{\multicolumn{3}{|c|}{$\begin{array}{l}\text { Mean Difference } \\
\text { IV, Fixed, } 95 \% \mathrm{CI}\end{array}$}} \\
\hline & Mean & SD & Total & Mean & SD & Total & Weight & IV, Fixed, $95 \% \mathrm{CI}$ & Year & & & \\
\hline SHL 2014 & 1.1 & 0.56 & 43 & 1.05 & 0.24 & 43 & $39.3 \%$ & $0.05[-0.13,0.23]$ & 2014 & & & \\
\hline YYK 2016 & 2.02 & 0.39 & 40 & 2.12 & 0.3 & 40 & $56.1 \%$ & $-0.10[-0.25,0.05]$ & 2016 & & 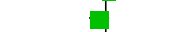 & \\
\hline HCL 2018 & 2.56 & 2.19 & 40 & 2.54 & 1.54 & 40 & $1.9 \%$ & $0.02[-0.81,0.85]$ & 2018 & & & \\
\hline ل لر 2018 & 2.05 & 1.44 & 30 & 2.08 & 1.31 & 30 & $2.7 \%$ & $-0.03[-0.73,0.67]$ & 2018 & & & \\
\hline Total $(95 \% \mathrm{Cl})$ & & & 153 & & & 153 & $100.0 \%$ & $-0.04[-0.15,0.08]$ & & & 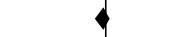 & \\
\hline $\begin{array}{l}\text { Heterogeneity: } \mathrm{Chi}^{2}= \\
\text { Test for overall effect }\end{array}$ & $\begin{array}{l}1.55, d \\
Z=0.6\end{array}$ & $\begin{array}{l}f=3 \\
53(P=\end{array}$ & $\begin{array}{l}(P=0 . \\
=0.53)\end{array}$ & 57); $1^{2}=$ & & & & & & -2 & $\begin{array}{cll}-1 & 0 & 1 \\
\mathrm{TCM}+\mathrm{WM} & & 1\end{array}$ & 2 \\
\hline
\end{tabular}

Fig. 14 TG before intervention 


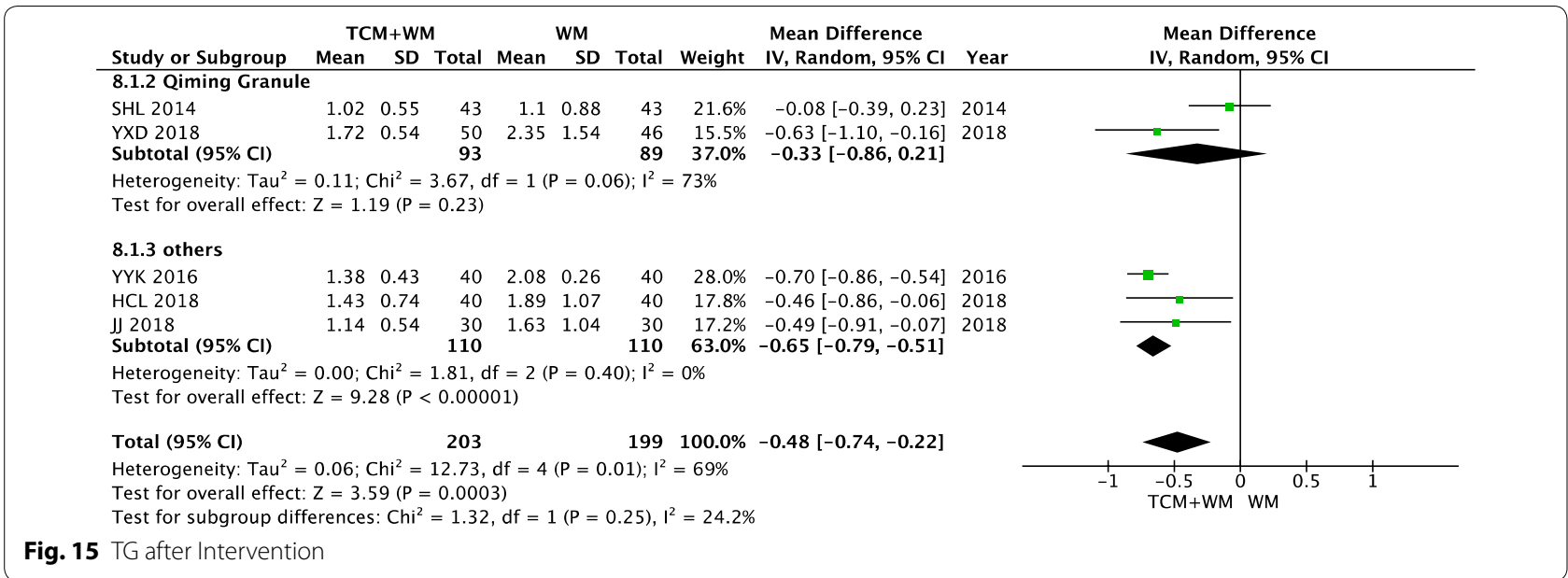

\begin{tabular}{|c|c|c|c|c|c|c|c|c|c|}
\hline \multirow[b]{2}{*}{ Study or Subgroup } & \multicolumn{3}{|c|}{ TCM+WM } & \multicolumn{3}{|c|}{ WM } & \multicolumn{3}{|c|}{ Mean Difference } \\
\hline & Mean & SD & Total & Mean & SD & Total & Weight & IV, Fixed, $95 \% \mathrm{CI}$ & Year \\
\hline SHL 2014 & 3.09 & 0.88 & 43 & 2.88 & 0.35 & 43 & $49.2 \%$ & $0.21[-0.07,0.49]$ & 2014 \\
\hline YYK 2016 & 6.5 & 0.88 & 40 & 6.22 & 0.81 & 40 & $28.7 \%$ & $0.28[-0.09,0.65]$ & 2016 \\
\hline HCL 2018 & 5.13 & 1.23 & 40 & 5.21 & 1.13 & 40 & $14.7 \%$ & $-0.08[-0.60,0.44]$ & 2018 \\
\hline J 2018 & 4.88 & 1.48 & 30 & 4.94 & 1.4 & 30 & $7.4 \%$ & $-0.06[-0.79,0.67]$ & 2018 \\
\hline Total $(95 \% \mathrm{Cl})$ & & & 153 & & & 153 & $100.0 \%$ & $0.17[-0.03,0.37]$ & \\
\hline
\end{tabular}

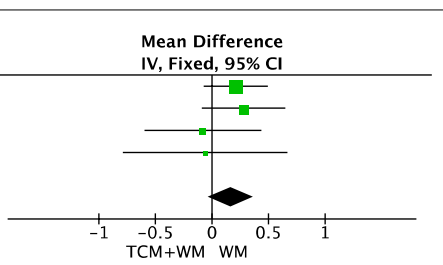

Fig. 16 TC before intervention

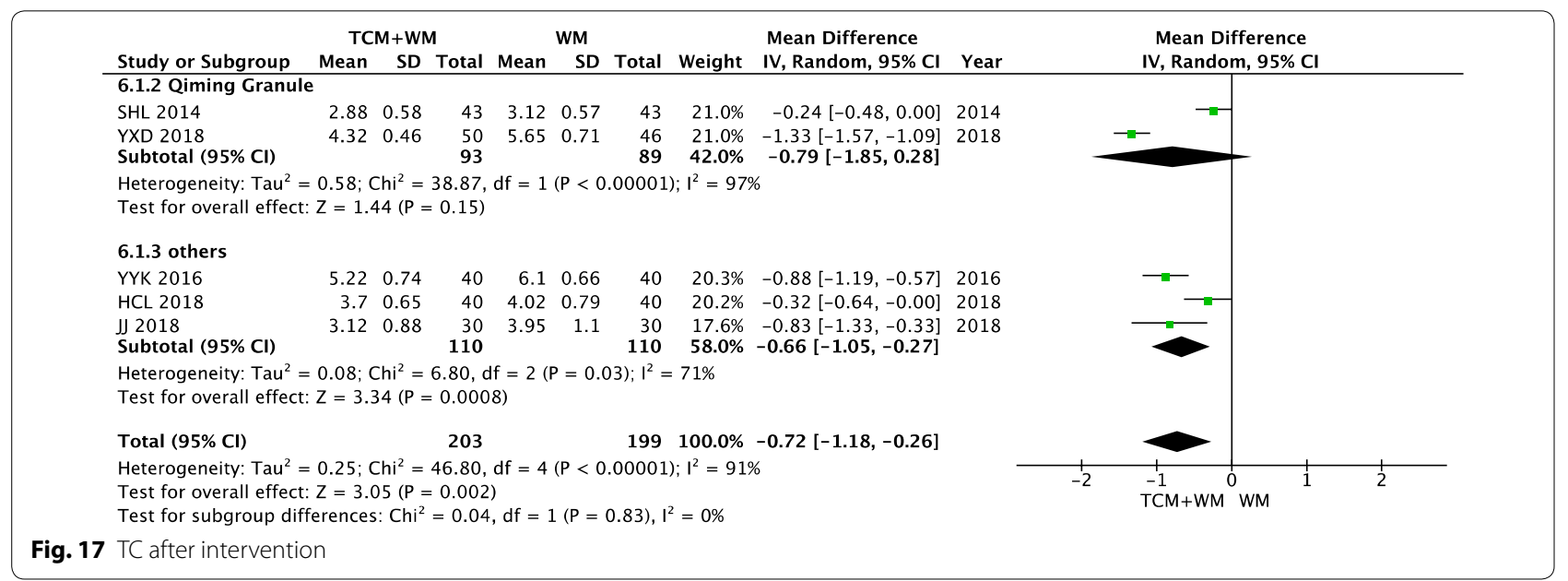

\begin{tabular}{|c|c|c|c|c|c|c|c|c|c|c|c|}
\hline & Study or Subgroup & \multicolumn{3}{|c|}{$\mathrm{TCM}+\mathrm{WM}$} & \multicolumn{3}{|c|}{ WM } & \multicolumn{3}{|c|}{ Mean Difference } & $\begin{array}{c}\text { Mean Difference } \\
\text { IV, Random, } 95 \% \mathrm{Cl}\end{array}$ \\
\hline & SHL 2014 & 1.6 & 0.52 & 43 & 1.5 & 0.46 & 43 & $41.9 \%$ & $0.10[-0.11,0.31]$ & 2014 & $\longrightarrow-$ \\
\hline & YYK 2016 & 0.96 & 0.32 & 40 & 1.04 & 0.37 & 40 & $58.1 \%$ & $-0.08[-0.23,0.07]$ & 2016 & \\
\hline & Total $(95 \% \mathrm{Cl})$ & & & 83 & & & 83 & $100.0 \%$ & $-0.00[-0.18,0.17]$ & & \\
\hline & \multicolumn{10}{|c|}{$\begin{array}{l}\text { Heterogeneity: } \text { Tau }^{2}=0.01 ; \mathrm{Chi}^{2}=1.88, \mathrm{df}=1(\mathrm{P}=0.17) ; \mathrm{I}^{2}=47 \% \\
\text { Test for overall effect: } \mathrm{Z}=0.05(\mathrm{P}=0.96)\end{array}$} & 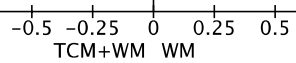 \\
\hline Fig. 18 & HDL before interv & ntion & & & & & & & & & \\
\hline
\end{tabular}




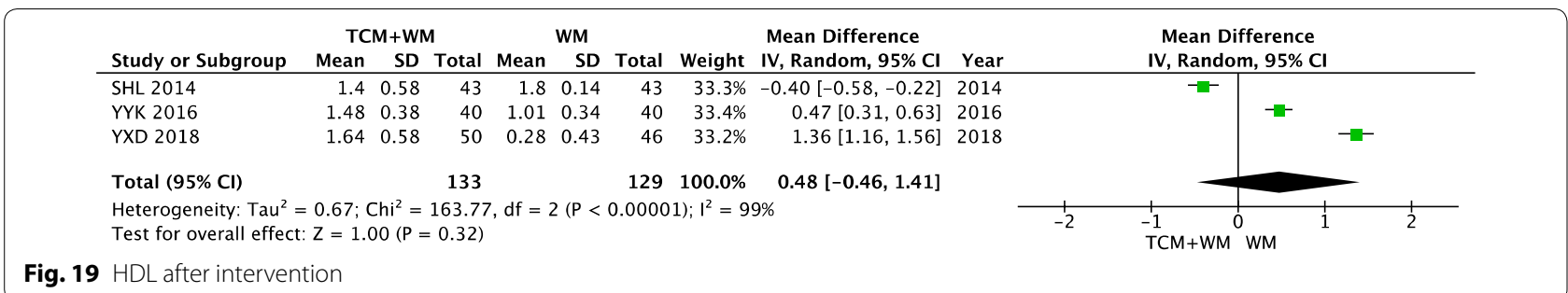

\begin{tabular}{|c|c|c|c|c|c|c|c|c|c|c|c|c|c|c|c|}
\hline & \multirow{2}{*}{$\begin{array}{l}\text { Study or Subgroup } \\
\text { SHL } 2014\end{array}$} & \multicolumn{3}{|c|}{$\mathrm{TCM}+\mathrm{WM}$} & \multicolumn{2}{|c|}{ WM } & Total & Weight & \multicolumn{2}{|l|}{ Mean Difference } & \multicolumn{4}{|c|}{$\begin{array}{l}\text { Mean Difference } \\
\text { IV, Fixed, } 95 \% \mathrm{Cl}\end{array}$} & \\
\hline & & 2.15 & 1.06 & 43 & 2.18 & 0.88 & 43 & $10.4 \%$ & $-0.03[-0.44,0.38]$ & 2014 & & & & & \\
\hline & YYK 2016 & 3.5 & 0.36 & 40 & 3.38 & 0.36 & 40 & $70.6 \%$ & $0.12[-0.04,0.28]$ & 2016 & & & - & & \\
\hline & HCL 2018 & 3.12 & 0.9 & 40 & 3.21 & 0.94 & 40 & $10.8 \%$ & $-0.09[-0.49,0.31]$ & 2018 & & & & & \\
\hline & 2018 J J & 2.76 & 0.96 & 30 & 2.82 & 0.87 & 30 & $8.2 \%$ & $-0.06[-0.52,0.40]$ & 2018 & & & & & \\
\hline & Total $(95 \% \mathrm{Cl})$ & & & 153 & & & 153 & $100.0 \%$ & $0.07[-0.07,0.20]$ & & & & & & \\
\hline & $\begin{array}{l}\text { Heterogeneity: } \mathrm{Chi}^{2} \\
\text { Test for overall effec }\end{array}$ & $\begin{array}{l}1.52, d \\
Z=0.9\end{array}$ & $\begin{array}{l}1 f=3 \\
99(P=\end{array}$ & $\begin{array}{l}(P=0 . \\
=0.32)\end{array}$ & 68); $1^{2}=$ & $=0 \%$ & & & & & -1 & $\begin{array}{l}-0.5 \\
T C M+W M\end{array}$ & 10 & 0.5 & 1 \\
\hline Fig. 20 & LDL before interve & ntion & & & & & & & & & & & & & \\
\hline
\end{tabular}

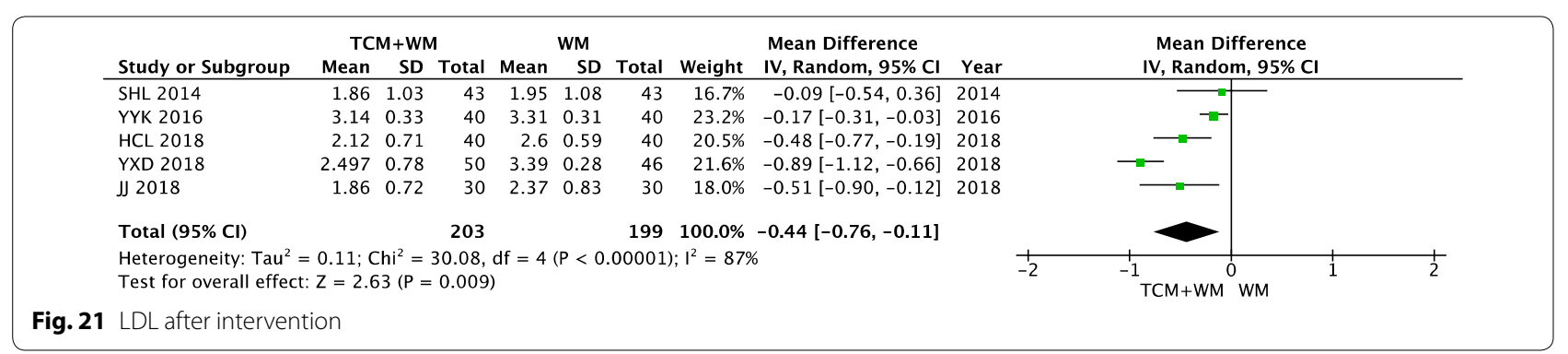

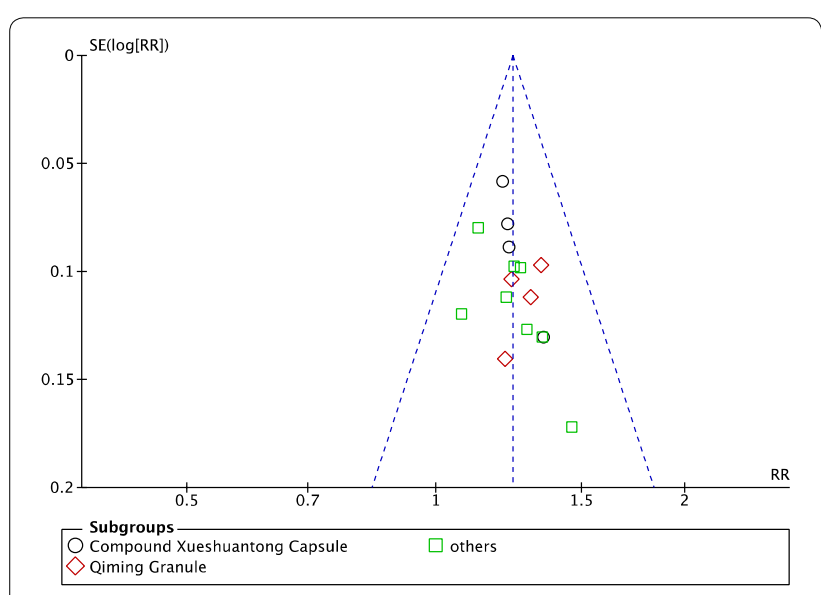

Fig. 22 Funnel plot of total efficacy

exudation, or cotton flocculent spots, while patients with PDR or DME may develop visual impairments. Vision-related findings may be present in patients with DME, but the researchers did not describe such a situation.

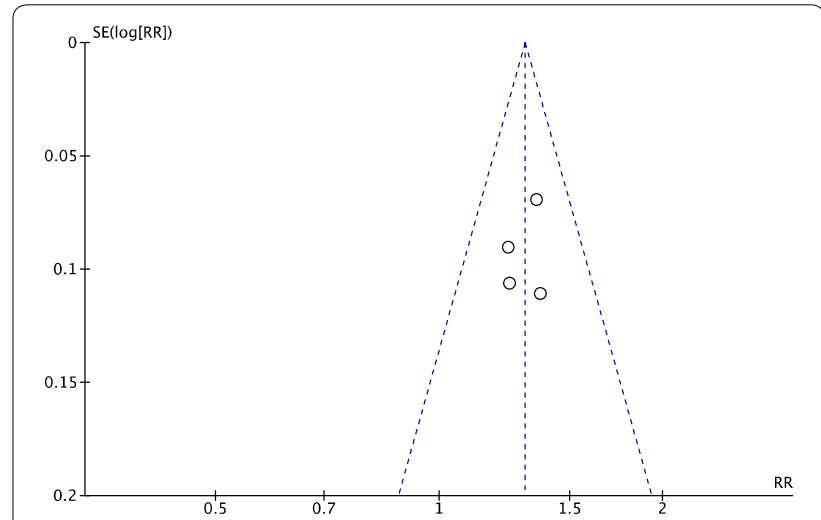

Fig. 23 Funnel plot of fundus effect

Funnel plots of overall efficacy and visual acuity showed basically symmetrical figures, but there was still a publication bias. In conclusion, TCM as an addon for NPDR is effective, safe, and worthy of clinical application. However, considering the low quality of current research and possible publication bias, caution is needed. 


\section{Conclusion}

NPDR is the main microvascular complication in patients with DN and needs special attention. Based on the lack of specific treatment for NPDR, there is a need for comprehensive intervention on the disease itself and corresponding risk factors. TCM with multiple targets plays a key role in the treatment of NPDR. The results of our systematic review and meta-analysis of current high-quality clinical studies showed that compared with WM alone, TCM + WM could significantly improve NPDR and also reduce the correlation levels of risk factors such as hyperglycemia or dyslipidemia. However, considering the small sample size in the study, there is a risk of publication bias, and our results should be treated with caution. In the future, we also believe that more high-quality studies should be included to enhance the reliability of the conclusions of this study.

\begin{abstract}
Abbreviations
DR: Diabetic retinopathy; NPDR: Non-proliferative diabetic retinopathy; WM: Western medicine; TCM: Traditional Chinese medicine; RCTs: Randomized controlled trials; DME: Diabetic macular edema; HbAlc: Glycosylated hemoglobin; CD: Calcium dobesilate; VEGF: Vascular endothelial growth factor; PRISMA: Preferred Reporting Project; CRBT: Cochrane Bias Risk Tool; MD: Mean difference; $\mathrm{Cl}$ : Confidence interval; RR: Relative risk; FBG: Fasting blood glucose; 2hPG: 2H-blood glucose; TG: Triglycerides; TC: Total cholesterol; HDL: High density lipoprotein; LDL: Low-density lipoprotein.
\end{abstract}

\section{Acknowledgements}

Not applicable.

\section{Authors' contributions}

FML and XLT designed the review protocol. DJ and LYD carried out the literature search. FML and XDA contributed to data extraction and quality assessment. RRZ, and SHZ provided statistical supports for meta-analysis. All authors read and approved the final manuscript.

\section{Funding}

This work was supported by the National Public Welfare Industry Special (201507001-11), National Traditional Chinese Medicine Administration of Traditional Chinese Medicine Science and Technology Research Project (2016ZX03). The funders had no role in the study design, data collection, data analysis, interpretation, or writing of the report.

\section{Availability of data and materials}

The data included original studies and meta-analysis file with TCM + WM for NPDR. The data used to support the findings of this study are available from the corresponding author upon request.

\section{Ethics approval and consent to participate}

Not applicable.

\section{Consent for publication}

Not applicable.

\section{Competing interests}

Not applicable.

\section{Author details}

${ }^{1}$ Department of Endocrinology, Guang'anmen Hospital, China Academy of Chinese Medical Sciences, Beijing 100053, China. ${ }^{2}$ China Academy of Chinese Medical Sciences, Beijing 100700, China. ${ }^{3}$ Beijing University of Chinese Medicine, Beijing 100029, China.
Received: 30 July 2020 Accepted: 11 September 2020

Published online: 17 September 2020

\section{References}

1. Guidelines for the prevention and treatment of type 2 diabetes in China (2017 edition). Chin J Pract Intern Med. 2018;38(04):292-344.

2. Fenwick EK, Pesudovs K, Rees G, Dirani M, Kawasaki R, Wong TY, et al. The impact of diabetic retinopathy: understanding the patient's perspective. Br J Ophthalmol. 2011;95(6):774-82.

3. Antonetti DA, Klein R, Gardner TW. Diabetic retinopathy. N Engl J Med. 2012;366(13):1227-399.

4. Yau JW, Rogers SL, Kawasaki R, Lamoureux EL, Kowalski JW, BekT, et al. Global prevalence and major risk factors of diabetic retinopathy. Diabetes Care. 2012;35(3):556-64.

5. Perrone L, Matrone C, Singh LP. Epigenetic modifications and potential new treatment targets in diabetic retinopathy. J Ophthalmol. 2014;2014:789120.

6. The relationship of glycemic exposure $(\mathrm{HbA} 1 \mathrm{c})$ to the risk of development and progression of retinopathy in the diabetes control and complications trial. Diabetes. 1995;44(8):968-83.

7. Effect of intensive blood-glucose control with metformin on complications in overweight patients with type 2 diabetes (UKPDS 34). UK Prospective Diabetes Study (UKPDS) Group. Lancet. 1998;352(9131):854-65.

8. Zhang HY, Wang JY, Ying GS, Shen LP, Zhang Z. Serum lipids and other risk factors for diabetic retinopathy in Chinese type 2 diabetic patients. J Zhejiang Univ Sci B. 2013;14(5):392-9.

9. Aiello LP, Edwards AR, Beck RW, Bressler NM, Davis MD, Ferris F, et al. Factors associated with improvement and worsening of visual acuity 2 years after focal/grid photocoagulation for diabetic macular edema. Ophthalmology. 2010;117(5):946-53.

10. Elman MJ, Qin H, Aiello LP, Beck RW, Bressler NM, Ferris FL 3rd, et al. Intravitreal ranibizumab for diabetic macular edema with prompt versus deferred laser treatment: three-year randomized trial results. Ophthalmology. 2012;119(11):2312-8

11. Yu X, Xu L, Zhou Q, Wu S, Tian J, Piao C, et al. The efficacy and safety of the Chinese herbal formula, JTTZ, for the treatment of type 2 diabetes with obesity and hyperlipidemia: a multicenter randomized, positivecontrolled. Open-Label Clin Trial Int J Endocrinol. 2018;2018:9519231.

12. Lian F, Wu L, Tian J, Jin M, Zhou S, Zhao M, et al. The effectiveness and safety of a danshen-containing Chinese herbal medicine for diabetic retinopathy: a randomized, double-blind, placebo-controlled multicenter clinical trial. J Ethnopharmacol. 2015;164:71-7.

13. Stewart LA, Clarke M, Rovers M, Riley RD, Simmonds M, Stewart G, et al. Preferred reporting items for systematic review and meta-analyses of individual participant data: the PRISMA-IPD statement. JAMA. 2015;313(16):1657-65.

14. Godlee F. The Cochrane collaboration. BMJ (Clin Res Ed). 1994;309(6960):969-70.

15. Furlan AD, Pennick V, Bombardier C, van Tulder M. 2009 updated method guidelines for systematic reviews in the Cochrane Back Review Group. Spine. 2009;34(18):1929-41.

16. Li H, Zhang Y, Tang M, Yue L, Yan P. Clinical observation on treatment of non-proliferative diabetic retinopathy by integrative Chinese and western medicine. J Hubei Univ Tradit Chin Med. 2019;21(02):72-4.

17. Sui $H$, Yu C, Xue H, Wang R. Clinical observation of Qiming granule combined with calcium hydroxybenzenesulfonate capsule in treating patients with nonproliferative diabetic retinopathy. Chin Med Innov. 2014;11(20):99-102.

18. Chen R. Clinical study on treatment of nonproliferative diabetic retinopathy by integrative Chinese and western medicine. Heilongjiang Med Sci. 2011;34(04):73-4.

19. Jia H. Clinical study on Ziyin Yiqi Tongluo recipe in treating non-proliferative diabetic retinopathy. Hebei Tradit Chin Med. 2014;36(12):1846-8.

20. Hu D, Ren F, Nan Y. Therapeutic effect of Mimenhuafang combined with calcium hydroxybenzenesulfonate capsule on non-proliferative diabetic retinopathy. Mod J Integr Tradit Chin West Med. 2017;26(18):1945-7.

21. Xiao L. Clinical observation of compound Xueshuantong combined with calcium hydroxybenzenesulfonate in the treatment of nonproliferative diabetic retinopathy. Jilin Med. 2016;37(09):2254-5. 
22. Wang Q. Effect of Qiming granule on non-proliferative diabetic retinopathy. Shenzhen J Integr Tradit Chin West Med. 2018;28(10):48-9.

23. Li W. Treatment of 38 cases of nonproliferative diabetic retinopathy with Qihuang Mingmu capsule. Hunan J Tradit Chin Med. 2015;31(03):72+83.

24. Zhang S. Clinical observation on treatment of nonproliferative diabetic retinopathy with combination of traditional Chinese medicine and western medicine. Hebei J Tradit Chin Med. 2011;26(02):29-30.

25. CS P, Zz Y. Clinical observation on treatment of nonproliferative diabetic retinopathy with Liangxue Sanyu decoction. Chin J Ophthalmol. 2013;23(03):169-72.

26. Jing J. Clinical observation of Yangyin Xiaoyu Mingmu recipe in treating nonproliferative diabetic retinopathy [master's degree]: Nanjing University of Chinese Medicine; 2018.

27. Jiang C, Li S. Clinical observation on treatment of nonproliferative diabetic retinopathy by integrative Chinese and western medicine. J Liaoning Univ Tradit Chin Med. 2009:11(06):179-80.

28. Yao Y. Therapeutic effect of Sanqi combined with Shengming on nonproliferative diabetic retinopathy [master's degree]: Nanjing University of Chinese Medicine; 2016

29. He C, Yin H, Zhang D, Zhang Y, Wang J, Wang S, et al. Effect of glycolipid square on the damage of non-proliferative diabetic retinopathy. China J Tradit Chin Med Inf. 2018;25(09):18-22.

30. Liu D, Zhou Q, Zhang Y. Effect of compound Xueshuantong combined with calcium hydroxybenzoate on the levels of HIF-1a and SDF-1 in nonproliferative diabetic retinopathy. Hebei Med. 2018;40(12):1838-41.

31. Yin X. Efficacy and safety evaluation of Qiming Granules combined with calcium dobesilate in the treatment of non-proliferative diabetic retinopathy. Med Theory Pract. 2018;31(01):83-4.

32. Wang Z. Qi Ming granule combined with calcium dobesilate in treatment of non-proliferative diabetic retinopathy. Int Eye Sci. 2017;17(4):702-5.

33. Ma J. Curative effect evaluation of compound Xueshuantong capsule combined with calcium dobesilate for patients with early diabetic retinopathy. Int Eye Sci. 2018:18(2):305-8.

34. Klein R, Klein BE, Moss SE, Davis MD, DeMets DL. The Wisconsin epidemiologic study of diabetic retinopathy. II. Prevalence and risk of diabetic retinopathy when age at diagnosis is less than 30 years. Arch Ophthalmol. 1984;102(4):520-6.

35. Zheng $Y$, He M, Congdon N. The worldwide epidemic of diabetic retinopathy. Indian J Ophthalmol. 2012;60(5):428-31.

36. Rohan TE, Frost CD, Wald NJ. Prevention of blindness by screening for diabetic retinopathy: a quantitative assessment. BMJ (Clin Res Ed). 1989:299(6709):1198-201.

37. Mohamed Q, Gillies MC, Wong TY. Management of diabetic retinopathy: a systematic review. JAMA. 2007;298(8):902-16.

38. Wang S, Xu L, Jonas JB, Wong TY, Cui T, Li Y, et al. Major eye diseases and risk factors associated with systemic hypertension in an adult Chinese population. Ophthalmology. 2009;116(12):2373-80.

39. Wong TY, Cheung CM, Larsen M, Sharma S, Simo R. Diabetic retinopathy. Nat Rev Dis Primers. 2016;2:16012.

40. Klein R, Knudtson MD, Lee KE, Gangnon R, Klein BE. The wisconsin epidemiologic study of diabetic retinopathy: XXII the twenty-five-year progression of retinopathy in persons with type 1 diabetes. Ophthalmology. 2008;115(11):1859-68.
41. Arar NH, Freedman BI, Adler SG, lyengar SK, Chew EY, Davis MD, et al. Heritability of the severity of diabetic retinopathy: the FIND-Eye study. Invest Ophthalmol Vis Sci. 2008:49(9):3839-45.

42. Keenan HA, Costacou T, Sun JK, Doria A, Cavellerano J, Coney J, et al. Clinical factors associated with resistance to microvascular complications in diabetic patients of extreme disease duration: the 50-year medalist study. Diabetes Care. 2007;30(8):1995-7.

43. Zhang L, Krzentowski G, Albert A, Lefebvre PJ. Risk of developing retinopathy in Diabetes Control and Complications Trial type 1 diabetic patients with good or poor metabolic control. Diabetes Care. 2001;24(7):1275-9.

44. Zhang X, Liu W, Wu S, Jin J, Li W, Wang N. Calcium dobesilate for diabetic retinopathy: a systematic review and meta-analysis. Sci China Life Sci. 2015;58(1):101-7.

45. Kumar B, Gupta SK, Saxena R, Srivastava S. Current trends in the pharmacotherapy of diabetic retinopathy. J Postgrad Med. 2012;58(2):132-9.

46. Javadzadeh A, Ghorbanihaghjo A, Adl FH, Andalib D, Khojasteh-Jafari H, Ghabili K. Calcium dobesilate reduces endothelin-1 and high-sensitivity C-reactive protein serum levels in patients with diabetic retinopathy. Mol Vis. 2013;19:62-8

47. Palanker D, Blumenkranz MS. Panretinal photocoagulation for proliferative diabetic retinopathy. Am J Ophthalmol. 2012;153(4):780-1 (author reply 1-2).

48. Bandello F, Preziosa C, Querques G, Lattanzio R. Update of intravitreal steroids for the treatment of diabetic macular edema. Ophthalmic Res. 2014;52(2):89-96.

49. Luo XX, Duan JG, Liao PZ, Wu L, Yu YG, Qiu B, et al. Effect of qiming granule on retinal blood circulation of diabetic retinopathy: a multicenter clinical trial. Chin J Integr Med. 2009;15(5):384-8.

50. Cao P. Changes of retinal vessel diameter in diabetic microvascular complications and the effect of Qiming granule intervention [Doctor]: Chengdu University of Traditional Chinese Medicine; 2016.

51. Hao GM, LvTT, Wu Y, Wang HL, Xing W, Wang Y, et al. The Hippo signaling pathway: a potential therapeutic target is reversed by a Chinese patent drug in rats with diabetic retinopathy. BMC Complement Altern Med. 2017:17(1):187.

52. Duan H, Huang J, Li W, Tang M. Protective effects of fufang xueshuantong on diabetic retinopathy in rats. Evid-Based Complement Altern Med. 2013:2013:408268.

53. Xia S, Hu S, Liao Y, Li S. Clinical effect analysis of compound Xueshuantong capsule in treating patients with diabetic retinopathy. Tradit Chin Med Clin Res. 2019;11(11):61-4.

\section{Publisher's Note}

Springer Nature remains neutral with regard to jurisdictional claims in published maps and institutional affiliations.

\footnotetext{
Ready to submit your research? Choose BMC and benefit from:

- fast, convenient online submission

- thorough peer review by experienced researchers in your field

- rapid publication on acceptance

- support for research data, including large and complex data types

- gold Open Access which fosters wider collaboration and increased citations

- maximum visibility for your research: over $100 \mathrm{M}$ website views per year
}

At BMC, research is always in progress.

Learn more biomedcentral.com/submissions 